\title{
Evaluation of the safety and efficacy of TRAIL and taurolidine use on human fibrosarcoma xenografts in vivo
}

\author{
KAMRAN HARATI ${ }^{1}$, SABINE EMMELMANN ${ }^{1}$, BJÖRN BEHR ${ }^{1}$, OLE GOERTZ ${ }^{1}$, TOBIAS HIRSCH ${ }^{1}$, \\ NICOLAI KAPALSCHINSKI ${ }^{1}$, JONAS KOLBENSCHLAG ${ }^{1}$, INGO STRICKER ${ }^{2}$, ANDREA TANNAPFEL $^{2}$, \\ MARCUS LEHNHARDT $^{1}$ and ADRIEN DAIGELER ${ }^{1}$ \\ ${ }^{1}$ Department of Plastic Surgery, Burn Center, Hand Center, Sarcoma Reference Center, \\ BG-University Hospital Bergmannsheil; ${ }^{2}$ Institute of Pathology, Ruhr-University Bochum, Bochum D-44789, Germany
}

Received December 31, 2014; Accepted December 16, 2015

DOI: $10.3892 / \mathrm{ol} .2016 .4118$

\begin{abstract}
Fibrosarcomas are rare malignant soft tissue tumours that exhibit a poor response to current therapeutic regimens. Previously, tumour necrosis factor-related apoptosis-inducing ligand (TRAIL) and taurolidine were observed to induce apoptosis synergistically in HT1080 human fibrosarcoma cells in vitro. Consequently, the present study aimed to assess the safety and efficacy of TRAIL in combination with taurolidine on the local growth of fibrosarcoma xenografts in vivo. HT1080 fibrosarcoma cells were inoculated subcutaneously into both flanks of 49 athymic nude mice in order to establish tumour xenografts. TRAIL and taurolidine were applied intraperitoneally at various single and cumulative treatment doses. After 12 days, the experiment was terminated and surviving animals were euthanised. Tumour progression was determined during and following treatment. To assess the potential toxic effects of the two compounds, the organs (lung, liver, kidney and heart) of all animals were examined histologically. The results revealed that combined treatment with TRAIL and taurolidine significantly inhibited the growth of HT1080 xenografts, whereas untreated animals had steadily increasing tumours. The most effective combination was TRAIL at $2 \mu \mathrm{g}$ per application (cumulative dose, $16 \mu \mathrm{g}$ ) and taurolidine at 30/15 mg per application (cumulative dose, $180 \mathrm{mg}$ ), reducing the mean size of implanted xenografts to $10.9 \mathrm{~mm}^{2}$ following treatment (vs. $48.9 \mathrm{~mm}^{2}$ in the control group; $\mathrm{P}=0.0100)$. Despite distinct tumour mass reduction, the rate of mortality was significantly increased in animals treated with TRAIL and taurolidine in a taurolidine dose-dependent manner; however, histological examinations of relevant organs revealed no evidence of systemic toxicity
\end{abstract}

Correspondence to: Dr Kamran Harati, Department of Plastic Surgery, Burn Center, Hand Center, Sarcoma Reference Center, BG-University Hospital Bergmannsheil, 1 Bürkle-de-la-Camp-Platz, Bochum D-44789, Germany

E-mail: kamran.harati@t-online.de

Key words: soft tissue sarcoma, fibrosarcoma, cancer, TRAIL, taurolidine, mice, toxicity, mortality (mean survival time, 7.9 days in the treated groups vs. 12 days in the control group; $\mathrm{P}<0.0010)$. In summary, whilst the combination of TRAIL and taurolidine synergistically inhibited the growth of fibrosarcoma xenografts in vivo, it was also accompanied by significantly increased mortality rate. Thus, although taurolidine is assumed to be a compound with an acceptable toxicity profile, and therefore increasingly used in clinical trials, the current findings raise concerns with regard to its safety and therapeutic index, and indicate the requirement for further detailed toxicity tests.

\section{Introduction}

Fibrosarcomas are rare soft tissue sarcomas originating from the intra- and intermuscular fibrous tissues, fascia and tendons. Every year, they account for $\sim 3 \%$ of all soft tissue sarcomas, which themselves represent $\sim 1 \%$ of all new cancer diagnoses in the United States and Europe (1-3). Due to their rarity, therapy for fibrosarcomas must be individualised and multimodal. At present, the standard therapy comprises surgical resection with a wide margin of healthy tissue, typically accompanied by radiation treatment in order to reduce the chance of local recurrence (4,5). Unfortunately, distant metastasis occurs in $\sim 50 \%$ of all patients, and surgical treatment is thus unavailable $(6,7)$.

In patients with metastatic disease, the median survival time with or without chemotherapeutic treatment is $<12$ months $(8,9)$. Few agents, such as doxorubicin, dacarbazine and ifosfamide, have been proven to be effective in the therapy of soft tissue sarcomas in general (4). However, these treatments have shown poor results and are rarely associated with significant improvements in overall survival (10). In disseminated disease, a response rate of $20-30 \%$ has been observed with doxorubicin, the most frequently used chemotherapeutic agent in the treatment of soft tissue sarcomas $(1,11)$. Furthermore, the combined use of doxorubicin and ifosfamide demonstrates greater efficacy, with higher response rates compared with those of doxorubicin alone; however, this treatment is associated with severe short- and long-term toxicities, including cardiomyopathy and bone marrow suppression (12-14). The recently published EORTC 62012 trial, which involved 455 patients with locally advanced, unresectable or metastatic 
high-grade soft-tissue sarcomas, concluded that an intensified therapy with doxorubicin and ifosfamide is unsuitable for palliation of advanced soft-tissue sarcomas due to the severe side effects, and should only be used when the specific goal is tumour shrinkage (14). Thus, the optimal treatment, particularly for metastatic or unresectable fibrosarcomas, remains to be defined.

The purpose of the present study was to determine the antitumour effects of tumour necrosis factor (TNF)-related apoptosis-inducing ligand (TRAIL) and taurolidine on HT1080 human fibrosarcoma xenografts in vivo, with the final aim of identifying a suitable combination for the treatment of disseminated fibrosarcomas. The apoptosis-inducing effects of TRAIL, which is a member of the TNF-superfamily, have been observed in a number of types of malignant cells (15-18). The receptors for TRAIL, death receptors 4 and 5, are oligomerised upon its binding, leading to the recruitment of FAS-associated protein with death domain to form a functional death-inducing signaling complex (DISC). Subsequently, DISC induces the activation of the extrinsic apoptosis pathway via caspase 8 (19-21).

Taurolidine, an antiseptic agent derived from the amino acid taurine, has been utilized for the treatment of peritonitis and catheter-related infections (22). Additionally, studies have demonstrated that taurolidine may be used effectively to treat certain malignant diseases (23-26). In numerous malignant cell lines, taurolidine treatment led to the inhibition of proliferation and the induction of cell death (23-25,27-31). Whilst its precise mechanism of action remains unclear, it appears to involve translational inhibition and various pathways of programmed cell death (28-30).

TRAIL and taurolidine represent a promising combined therapy able to exert synergistic apoptotic effects on various types of malignant cells in vitro, including soft tissue sarcoma cell lines, such as HT1080 fibrosarcoma (32-35). In studies conducted in vitro, the combination of TRAIL and taurolidine was revealed to result in sustained cell death, and this was superior to single treatment with TRAIL or taurolidine, despite the lower concentrations of the two substances used in the combination trials $(32,33,36)$. Experimental findings have also demonstrated that combined treatment with taurolidine may reduce the potential toxic side effects of TRAIL by reducing the required optimal dose of TRAIL, and by modulating its effector pathways without affecting the efficacy of its antitumour activity (33).

Inspired by these results, the present study examined the antitumour effects of the two compounds in different single and cumulative treatment doses on human fibrosarcoma xenografts in athymic nude mice.

\section{Materials and methods}

Cell culture. HT1080 human fibrosarcoma cells were purchased from the American Type Culture Collection (ATCC; Wesel, Germany; cell line CCL-121) and maintained in minimal essential medium (Biowest, Nuaillé, France); containing $10 \%$ foetal bovine serum (Pan-Biotech $\mathrm{GmbH}$, Aidenbach, Germany) supplemented with $1 \%$ penicillin (100 U/ml; Sigma-Aldrich, St. Louis, MO, USA) and streptomycin $(100 \mu \mathrm{g} / \mathrm{ml}$; Sigma-Aldrich) as well as $1 \%$ L-glutamine
(Sigma-Aldrich). The cells were grown to a sub-confluent monolayer and maintained at $37^{\circ} \mathrm{C}$ in a humidified atmosphere of $5 \% \mathrm{CO}_{2}$.

Reagents. Taurolidine (Taurolin ${ }^{\circledR} 2 \%$; Boehringer Ingelheim Pharma GmbH \& Co. KG, Ingelheim, Germany) containing $5 \%$ Povidon was used as supplied by the manufacturer. Recombinant human TRAIL (Bender MedSystems GmbH, Vienna, Austria) was dissolved in distilled water according to the manufacturer's instructions. Phosphate-buffered saline (GE Healthcare Life Sciences, Pasching, Austria) was applied in equal volume as a control substance.

Animals. The treated animals were congenitally athymic nude mice (Foxn1 ${ }^{\text {nu/nu }}$; Harlan Winkelmann $\mathrm{GmbH}$, Borchen, Germany), 5 weeks of age and weighing 20-25 g. The animals were housed in ventilated, pathogen-free racks under a $12 \mathrm{~h}$ light-dark photoperiodicity with controlled humidity (50-60\%) and temperature $\left(22-24^{\circ} \mathrm{C}\right)$. The animals were allowed sterile food (Ssniff Spezialdiäten $\mathrm{GmbH}$, Soest, Germany) and water ad libitum. All animals were acclimated for 8 days under these conditions prior to commencing the investigations. Injections and other manipulations were conducted aseptically inside a laminar flow hood (Tecniplast, Hohenpeißenberg, Germany).

The experimental procedures were conducted with strict adherence to the rules and guidelines for the ethical use of animals in research according to the German animal welfare law (Tierschutzgesetz), and were approved by the State Office of Nature, Environment and Consumer Protection of the German State of North Rhine-Westphalia (permission number, 9.93.2.10.32.07.151).

HT1080 xenograft model. HT1080 cell suspensions were injected subcutaneously $\left(1 \times 10^{6}\right.$ cells $)$ into the right and left flanks of the athymic nude mice to establish xenograft tumours and simulate disseminated disease. Each day, mice were weighed and tumour area was determined with a Vernier caliper. Tumour area was calculated based on the following equation: Tumour area $\left(\mathrm{mm}^{2}\right)=$ length (long axis) $\mathrm{x}$ width (short axis).

Toxicity testing. To evaluate the potential toxic effects of TRAIL and taurolidine, 6 athymic nude mice without xenografts received intraperitoneal (i.p.) injections of $15 \mathrm{mg}$ taurolidine and $1 \mu \mathrm{g}$ TRAIL on 3 days/week for 4 weeks, resulting in a cumulative taurolidine dose of $180 \mathrm{mg}$ and TRAIL dose of $12 \mu \mathrm{g}$ per animal within 28 days. Animals were examined daily, body weights were recorded thrice weekly, feed and water usage once a week. A reduction in body weight of $>10 \%$ was considered significant. A complete blood count was performed prior to and following treatment. At 4 weeks after therapy initiation, all mice were euthanised. Kidney, liver and skin samples were retrieved and histologically examined.

Histological examination. Mice were euthanised under gas anaesthesia with narcoren (Merial GmbH, Hallbergmoos, Germany). Final body weight, as well as the tumour size, were measured. Excised tumours and organs (heart, lung, liver, kidney and skin samples) were fixed in $5 \%$ buffered 


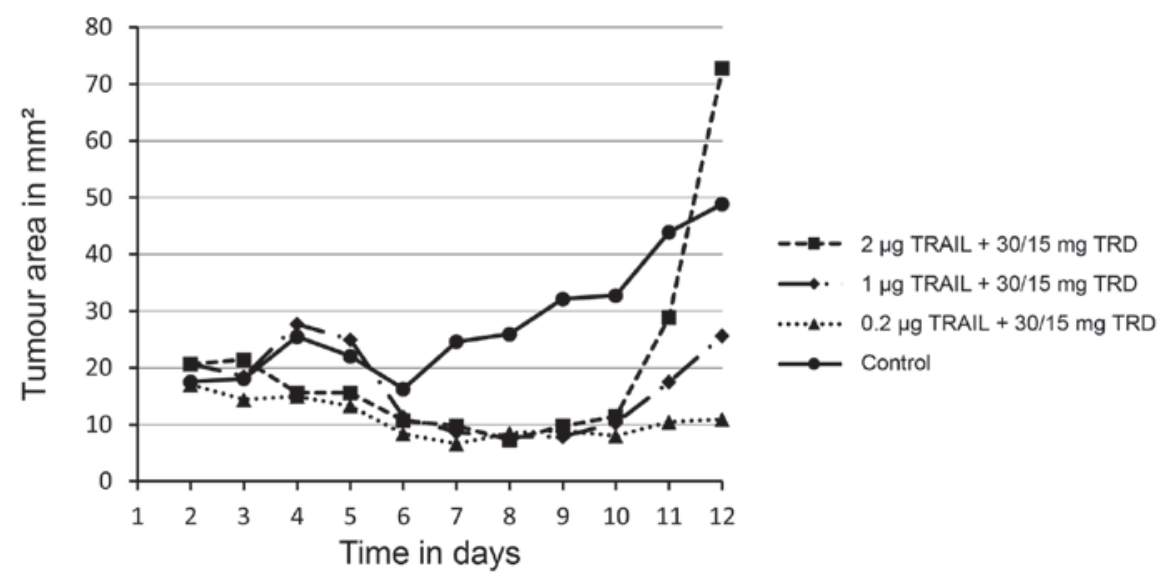

Figure 1. Antitumour efficacy of different dosages of TRAIL and taurolidine on HT1080 human fibrosarcoma xenografts. A total of 40 athymic nude mice with subcutaneous xenografts on both flanks were randomized into one control group (10 animals), and three treatment groups (each 10 animals). From 1 day after tumour inoculation, the first 4-day cycle of treatment with different single doses of TRAIL ( $0.2,1$ or $2 \mu \mathrm{g} /$ injection) and a consistent daily dose of $30 \mathrm{mg}$ taurolidine was initiated. Following a break of 2 days the second cycle continued with the same doses of TRAIL ( $0.2,1$ or $2 \mu \mathrm{g} / \mathrm{injection})$ and a consistent daily dose of $15 \mathrm{mg}$ taurolidine for another 4 days. After another 2 days (on day 12) outliving animals were euthanised. Control animals received phosphate-buffered saline at equal volumes. Tumour area was determined daily with a Vernier caliper and after death histologically. The results of tumour growth progression are represented as the means of 20 tumours in each group. TRAIL, tumour necrosis factor-related apoptosis-inducing ligand; TRD, taurolidine.

formaldehyde. Paraffin-embedded 2-3- $\mu \mathrm{m}$ sections were stained with haematoxylin and eosin for histological examination.

Treatment. The antitumour activity of different doses of combined TRAIL and taurolidine was analysed in the HT1080 xenografts. In the first series, varying doses of TRAIL $(0.2,1$ or $2 \mu \mathrm{g} /$ injection) were applied i.p. with a consistent dose of taurolidine $(30 \mathrm{mg} / \mathrm{injection}$ in the first 4-day cycle and $15 \mathrm{mg}$ /injection in the second 4-day cycle) within a time range of 12 days in 40 mice bearing $n=80$ xenografts. From day 1 after tumour inoculation, TRAIL was administered daily at $0.2,1$ or $2 \mu \mathrm{g} /$ injection in combination with $30 \mathrm{mg}$ /injection taurolidine for 4 days. Following a break of 2 days, treatment was continued with administration of TRAIL at $0.2,1$ or $2 \mu \mathrm{g} /$ injection and taurolidine at $15 \mathrm{mg}$ /injection for another 4 days. Accordingly, the first series consisted of one control group and three treatment groups (each $\mathrm{n}=20$ ) with different cumulative dosages of TRAIL (1.6, 8 or $16 \mu \mathrm{g}$ ) but the same cumulative dosage of taurolidine $(180 \mathrm{mg})$. Similarly, in the second series, varying doses of taurolidine $(15,20$ or $25 \mathrm{mg} /$ injection) were applied with a consistent dose of TRAIL ( $2 \mu \mathrm{g} /$ injection) within a time range of 12 days in 9 mice bearing a total of 18 xenografts. With the exception of dosage, all procedures were performed the same way as in the first series. The second series consisted of three treatment groups (each $n=6$ ) with different cumulative dosage of taurolidine ( $120 \mathrm{mg}, 160 \mathrm{mg}$ or $200 \mathrm{mg}$ ) but the same cumulative dosage of TRAIL (16 $\mu \mathrm{g})$. Tumour area and body weight were recorded daily, feed and water usage weekly. At 12 days after the beginning of treatment, all surviving animals were euthanised and tumour, liver, heart, lung, kidney and skin samples were removed and histologically examined.

Statistical analysis. SPSS version 18 (SPSS, Inc., Chicago, IL, USA) was used for statistical analysis. Comparisons between experimental groups and trend lines were performed using one-way analysis of variance and Tukey's post hoc test. $\mathrm{P} \leq 0.05$ was considered to indicate a statistically significant difference.

\section{Results}

I.p. injections of TRAIL and taurolidine are well-tolerated in athymic nude mice without fibrosarcoma xenografts. In the preliminary toxicity tests, combined administration of $15 \mathrm{mg}$ taurolidine and $1 \mu \mathrm{g}$ TRAIL i.p. was not associated with any acute toxic events. Furthermore, the cumulative doses of $12 \mu \mathrm{g}$ TRAIL and $180 \mathrm{mg}$ taurolidine applied within 28 days were also well-tolerated by the 6 tested immunosuppressed mice. No significant weight losses or changes in feed and water usage were observed. Only 1 animal died on day 22 of treatment during anaesthesia. Otherwise, there was no evidence for significantly increased mortality. Skin samples, liver and kidneys exhibited no relevant histological changes, and a complete blood count revealed no pathological alterations (data not shown).

Combined TRAIL and taurolidine treatment leads to marked tumour growth inhibition in a TRAIL dose-dependent manner, but is associated with significantly increased mortality. Treatment with varying doses of TRAIL $(0.2 \mu \mathrm{g}$, $1 \mu \mathrm{g}$ or $2 \mu \mathrm{g}$ /injection) and a consistent dose of taurolidine (30 $\mathrm{mg}$ and $15 \mathrm{mg} /$ injection) significantly decreased the size of the inoculated xenografts when compared with the untreated control group $(0.2 \mu \mathrm{g}, \mathrm{P}=0.0010 ; 1 \mu \mathrm{g}, \mathrm{P}=0.0080$; $2 \mu \mathrm{g}, \mathrm{P}=0.0100$ ) (Figs. 1 and 2). Of the 58 successfully inoculated xenografts, 34 exhibited a complete remission when examined histologically following the treatment. The growth of a further 14 tumours was inhibited significantly, whereas only 10 tumours increased steadily. In the control group, 17 of 20 implanted xenografts exhibited a sustained growth. The antitumoural effect was observed in a TRAIL dose-dependent manner; however, the differences between the treatment groups with various TRAIL dosages were not statistically significant. Treatment with $2 \mu \mathrm{g}$ TRAIL and $30 \mathrm{mg} / 15 \mathrm{mg}$ taurolidine reduced the mean size of implanted xenografts to $10.9 \mathrm{~mm}^{2}$, compared to $48.9 \mathrm{~mm}^{2}$ in the control group $(\mathrm{P}=0.0100)$ (Fig. 1). 
A

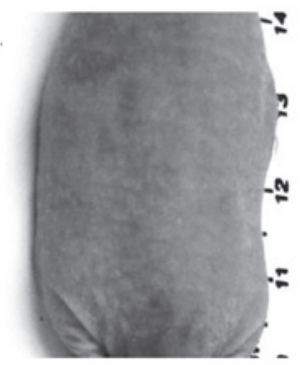

B

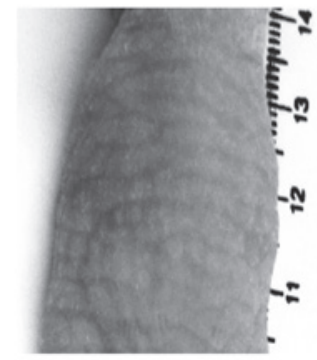

C

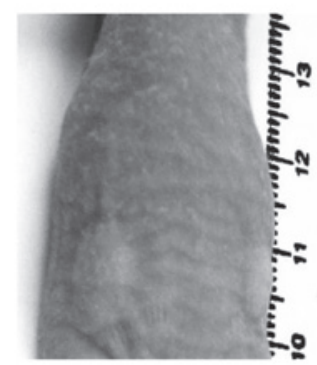

D

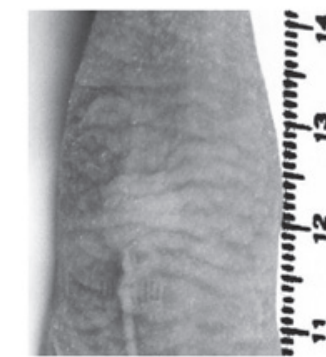

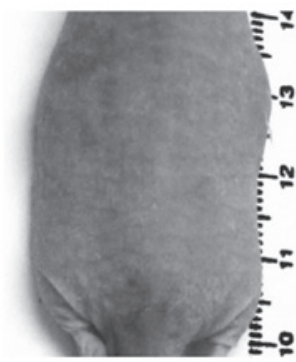
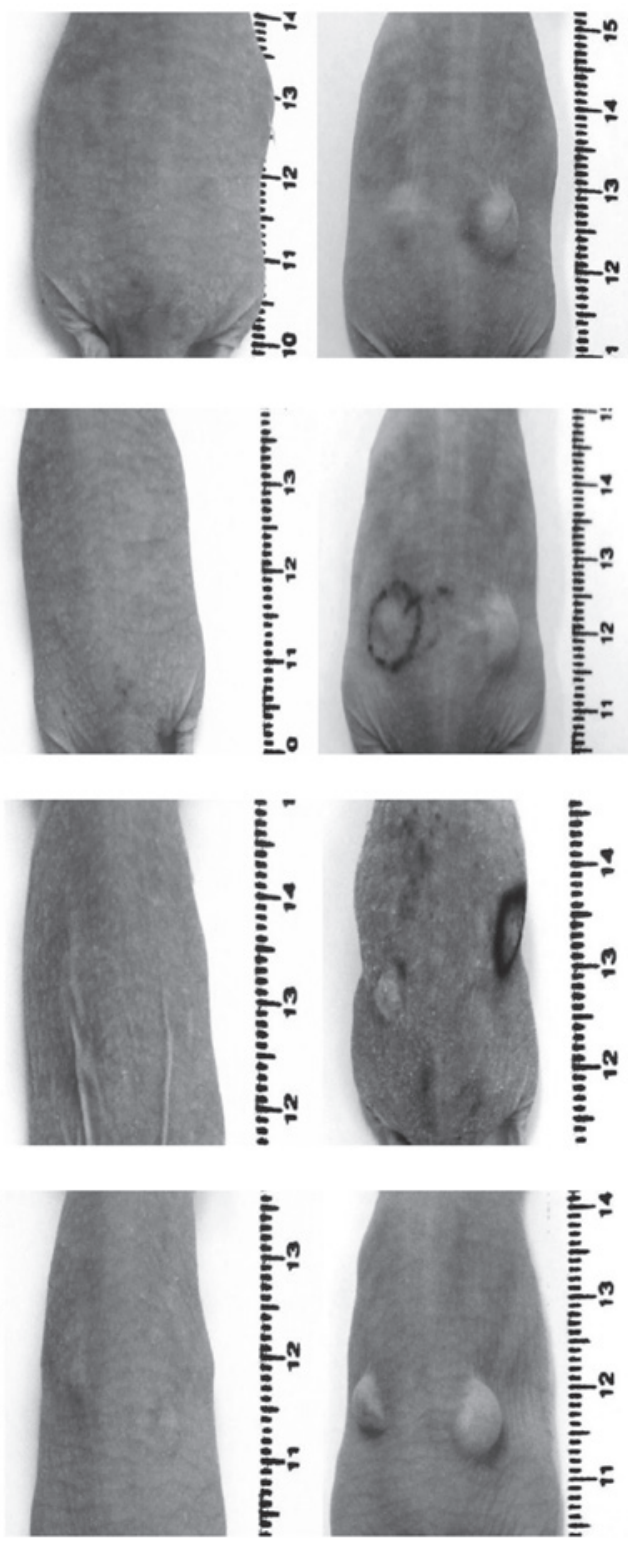

Figure 2. Representative photographs of tumour progression in the different treatment groups. Photographs show tumour status and growth of the different treatment groups on days 1, 7 and 12 (from left to right) following inoculation: (A) Treatment with $0.2 \mu \mathrm{g}$ TRAIL and 30/15 mg taurolidine; (B) treatment with $1 \mu \mathrm{g}$ TRAIL and 30/15 mg taurolidine; (C) treatment with $2 \mu \mathrm{g}$ TRAIL and 30/15 mg taurolidine; (D) control mouse treated with phosphate-buffered saline at equal volumes. TRAIL, tumour necrosis factor-related apoptosis-inducing ligand.

Notably, 24 of the 30 animals died during the combination treatment with TRAIL $(0.2 \mu \mathrm{g}, 1 \mu \mathrm{g}$ or $2 \mu \mathrm{g} /$ injection $)$ and taurolidine (30 $\mathrm{mg}$ and $15 \mathrm{mg}$ /injection). The mean survival times were 7.5 days $(0.2 \mu \mathrm{g}$ TRAIL, $30 / 15 \mathrm{mg}$ taurolidine), 8.3 days ( $1 \mu \mathrm{g}$ TRAIL, $30 / 15 \mathrm{mg}$ taurolidine) and 7.9 days (0.2 $\mu \mathrm{g}$ TRAIL, $30 / 15 \mathrm{mg}$ taurolidine) in the three treatment groups. Despite the steadily growing tumours, all 10 control animals were alive at day 12 and were euthanised for further investigations. The mortality rate was significantly higher in the treatment groups compared with the control group $(0.2 \mu \mathrm{g}$, $\mathrm{P}<0.0001 ; 1 \mu \mathrm{g}, \mathrm{P}<0.0020 ; 2 \mu \mathrm{g}, \mathrm{P}<0.0010)$. Furthermore, the treated animals exhibited a significant loss in body weight compared with untreated animals $(\mathrm{P}<0.0001)$ (data not shown). This was accompanied by significantly decreased feed $(0.2 \mu \mathrm{g}$, $\mathrm{P}=0.0020 ; 1 \mu \mathrm{g}, \mathrm{P}=0.0050 ; 2 \mu \mathrm{g}, \mathrm{P}=0.0040)$ and water usage $(0.2 \mu \mathrm{g}, \mathrm{P}=0.0070 ; 1 \mu \mathrm{g}, \mathrm{P}=0.0020 ; 2 \mu \mathrm{g}, \mathrm{P}<0.0010)$ by treated animals (data not shown).
Increase of taurolidine dosage exerts no additive effects on tumour growth inhibition and is associated with diminished survival. Tumour growth was unaffected by altering taurolidine dosage (Fig. 3). All 3 animals in the treatment group with the highest taurolidine dosage $(25 \mathrm{mg} /$ injection in combination with $2 \mu \mathrm{g}$ TRAIL) died within 8 days and exhibited a mean body-weight loss of $15.6 \%$. In addition, the feed and water usage of this group was significantly lower when compared with that of the other groups $(\mathrm{P}<0.0010)$ (data not shown). Animals exposed to lower taurolidine dosage (15 mg or $20 \mathrm{mg}$ /injection) survived through the 12 days of treatment. However, in these treatment groups, xenografted tumours grew continuously.

Histological analyses of organs reveal no clear evidence for systemic toxic damages. The histological examinations classified all successfully inoculated tumours as human 


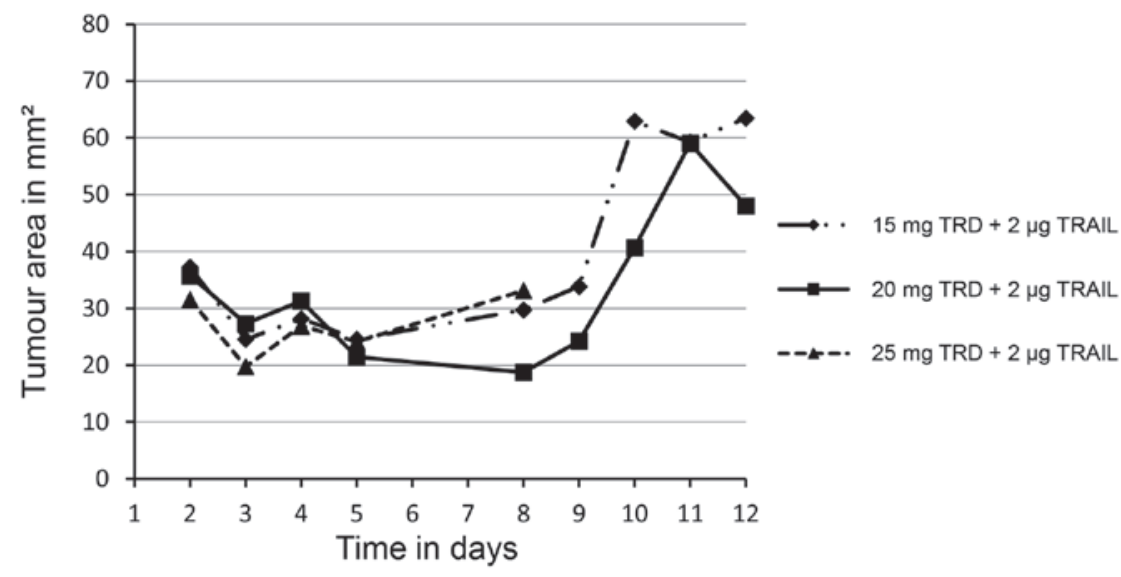

Figure 3. Antitumour efficacy of different dosages of TRAIL and taurolidine on HT1080 human fibrosarcoma xenografts. A total of 9 athymic nude mice with subcutaneous xenografts on both flanks were randomized into three treatment groups (each 3 animals). Different doses of taurolidine (15, $20 \mathrm{or} 25 \mathrm{mg} / \mathrm{injec}-$ tion) were applied intraperitoneally with a consistent daily dose of $2 \mu \mathrm{g}$ TRAIL in the same regime as in Fig. 1. Tumour area was determined daily with a Vernier caliper and following death histologically. The results of tumour growth progression are represented as the mean from each group. TRAIL, tumour necrosis factor-related apoptosis-inducing ligand; TRD, taurolidine.

fibrosarcomas (Fig. 4). The skin samples, hearts and livers of all animals exhibited no histological abnormalities. Notably, in the majority of the treated animals, oedema was observed in the tubulus system of the kidneys in the absence of any evidence for necrosis. By contrast, none of the control animals had an altered tubulus system. Small liver necrosis under the capsule was detected only in a few treated mice. However, the majority of the treated mice did not display any toxic organ damages. Overall, no relevant toxic organ alterations that may be causative of the mortality of the treated mice were observed.

\section{Discussion}

Fibrosarcomas are rare tumours and respond poorly to chemotherapy and radiation. Despite excellent rates of local disease control, treatment options in distant metastatic disease, particularly in pulmonary locations, are extremely limited and have an associated median survival of $<12$ months $(8,9)$. Due to the rarity of fibrosarcomas, the development of new therapeutics has been challenging, and the lack of novel chemotherapy protocols remains a major problem.

In a previous experimental study, our group demonstrated that TRAIL and taurolidine synergistically induced apoptosis and inhibited cell proliferation of HT1080 fibrosarcoma cells in vitro (36). Inspired by these results, the present study treated human fibrosarcoma xenografts in athymic nude mice with TRAIL and taurolidine in order to evaluate the safety and antitumour efficacy of these two compounds. The first step of the current study analysed the potential systemic toxic effects exerted by the combination of these two substances. Tested in athymic nude mice without xenografts, a cumulative dosage of $180 \mathrm{mg}$ taurolidine and $12 \mu \mathrm{g}$ TRAIL per animal applied i.p. within 28 days was well-tolerated. In the second step, the combination of the two compounds administered in the same and slightly different cumulative dosages was examined in athymic nude mice bearing HT1080 fibrosarcoma xenografts. Due to the rapid growth of the fibrosarcoma xenografts, the cumulative dosages were applied within 12 days instead of the previously tested, and initially intended, 28 days, resulting in

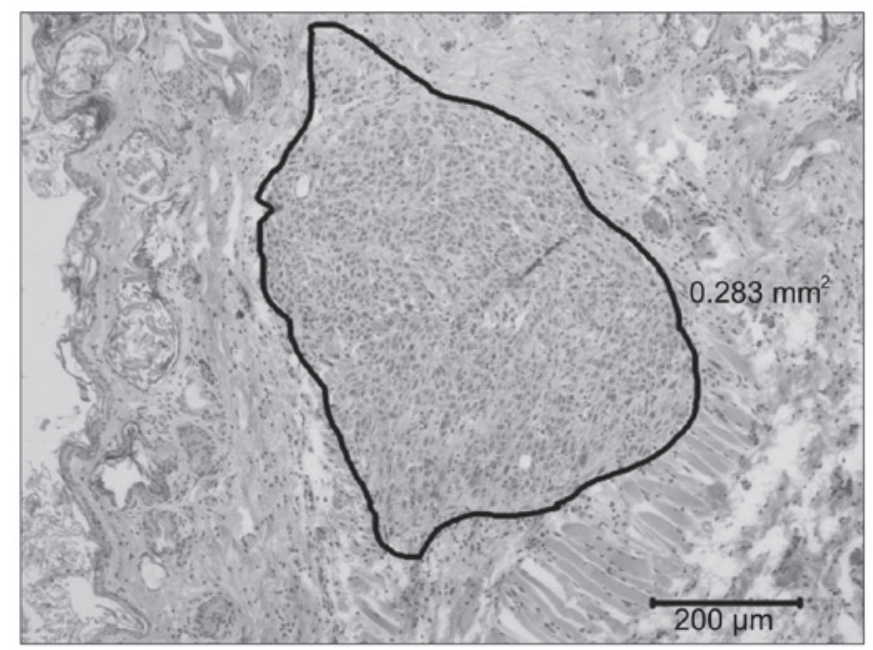

Figure 4. Haematoxylin and eosin staining of HT1080 xenograft. Histological examination revealed that the xenografts were mesenchymal tumours with typically spindle-shaped morphology, predominantly small ovoid nuclei and pressed cytoplasm.

shorter dosing intervals and higher cumulative dose intensities (CDIs). Here, treatment with TRAIL and taurolidine reduced tumour growth significantly in a TRAIL dose-dependent manner when comparing the growth rates. However, treatment with TRAIL and taurolidine was associated with a severely increased mortality rate, raising concern regarding the used CDI and the safety of the two compounds. However, reconsidering the current findings and the results of previous in vivo studies, increased mortality was associated primarily with high dosages of taurolidine. In two previous studies, the antineoplastic effects of taurolidine were analysed in athymic nude mice weighing 20-25 g. Cumulative dosages of $180 \mathrm{mg}$ (applied via nine 20-mg i.p. injections within 21 days) and $105 \mathrm{mg}$ (applied via seven 15-mg i.p. injections within 14 days) were well-tolerated with no significant mortality $(37,38)$. Single doses were applied i.p. and ranged from 15 to $20 \mathrm{mg}$. Notably, $20 \mathrm{mg}$ taurolidine per injection and day was identified by Calabresi et al (27) to be the maximally tolerated 
dose in athymic nude mice, with a mortality of $13 \%$ following 3 days of treatment (CDI, $60 \mathrm{mg} / 3$ days). By contrast, $30 \mathrm{mg}$ taurolidine per injection and day resulted in a mortality rate of $100 \%$ following 3 days of treatment (CDI, $90 \mathrm{mg} / 3$ days). In the current study, effective antineoplastic treatment required applications of $30 \mathrm{mg}$ taurolidine per injection and day for 4 subsequent days (CDI, $120 \mathrm{mg} / 4$ days); however animals treated with this dosage of taurolidine exhibited a markedly increased mortality rate. These findings correlate with the results of Calabresi et al (27) and indicate that the high mortality rate was attributable to the high CDI of taurolidine. Nevertheless, in the present study, drug-related mortality was not accompanied by histologically detectable damage to the examined organs (heart, lungs, liver, kidneys and skin). Notably, lower taurolidine dosage did not increase mortality, but also failed to inhibit tumour growth.

Although taurolidine has been assumed to be well-tolerated, severe side effects have been observed in preclinical studies (39-41). In a recent study evaluating the antineoplastic effects of taurolidine in immunocompetent mice with osteosarcoma, taurolidine was associated with severe liver toxicity, with a notable increase of liver enzymes, and led to pathological alterations of hepatocytes as detected by electron microscopy (39). Further studies assessing the safety of taurolidine in dogs and canines with osteosarcoma demonstrated that taurolidine enhanced the systemic toxicity of chemotherapeutics like doxorubicin and carboplatin $(40,41)$. Although initial clinical tests in humans reported low toxicity (42-45), the present findings suggest that cautious use is advisable, and raise concern with regard to the therapeutic index of taurolidine, which must be analysed by forthcoming studies with detailed toxicity tests.

\section{References}

1. Nedea EA and DeLaney TF: Sarcoma and skin radiation oncology. Hematol Oncol Clin North Am 20: 401-429, 2006.

2. Jemal A, Siegel R, Ward E, Murray T, Xu J and Thun MJ: Cancer statistics, 2007. CA Cancer J Clin 57: 43-66, 2007.

3. Gronchi A, Casali PG, Mariani L, Miceli R, Fiore M, Lo Vullo S, Bertulli R, Collini P, Lozza L, Olmi P and Rosai J: Status of surgical margins and prognosis in adult soft tissue sarcomas of the extremities: A series of patients treated at a single institution. J Clin Oncol 23: 96-104, 2005.

4. Patrikidou A, Domont J, Cioffi A and Le Cesne A: Treating soft tissue sarcomas with adjuvant chemotherapy. Current Treat Options Oncol 12: 21-31, 2011.

5. Kaushal A and Citrin D: The role of radiation therapy in the management of sarcomas. Surg Clin North Am 88: 629-646, 2008.

6. O'Brien GC, Cahill RA, Bouchier-Hayes DJ and Redmond HP. Co-immunotherapy with interleukin-2 and taurolidine for progressive metastatic melanoma. Ir J Med Sci 175: 10-14, 2006.

7. Solomon LR, Cheesbrough JS, Bhargava R, Mitsides N, Heap M, Green G and Diggle P: Observational study of need for thrombolytic therapy and incidence of bacteremia using taurolidine-citrate-heparin, taurolidine-citrate and heparin catheter locks in patients treated with hemodialysis. Semin Dial 25: 233-238, 2012.

8. Karavasilis V, Seddon BM, Ashley S, Al-Muderis O, Fisher C and Judson I: Significant clinical benefit of first-line palliative chemotherapy in advanced soft-tissue sarcoma: Retrospective analysis and identification of prognostic factors in 488 patients. Cancer 112: 1585-1591, 2008.

9. Billingsley KG, Lewis JJ, Leung DH, Casper ES, Woodruff JM and Brennan MF: Multifactorial analysis of the survival of patients with distant metastasis arising from primary extremity sarcoma. Cancer 85: 389-395, 1999.
10. Pezzi CM, Pollock RE, Evans HL, Lorigan JG, Pezzi TA, Benjamin RS and Romsdahl MM: Preoperative chemotherapy for soft-tissue sarcomas of the extremities. Ann Surg 211: 476-481, 1990.

11. Donato Di Paola E and Nielsen OS; EORTC Soft Tissue and Bone Sarcoma Group: The EORTC soft tissue and bone sarcoma group. European organisation for research and treatment of cancer. Eur J Cancer 38 (Suppl 4): S138-S141, 2002.

12. Brodowicz T, Schwameis E, Widder J, Amann G, Wiltschke C, Dominkus M, Windhager R, Ritschl P, Pötter R, Kotz R and Zielinski CC: Intensified adjuvant IFADIC chemotherapy for adult soft tissue sarcoma: A prospective randomized feasibility trial. Sarcoma 4: 151-160, 2000.

13. Frustaci S, Gherlinzoni F, De Paoli A, Bonetti M, Azzarelli A, Comandone A, Olmi P, Buonadonna A, Pignatti G, Barbieri E, et al: Adjuvant chemotherapy for adult soft tissue sarcomas of the extremities and girdles: Results of the Italian randomized cooperative trial. J Clin Oncol 19: 1238-1247, 2001.

14. Judson I, Verweij J, Gelderblom H, Hartmann JT, Schöffski P, Blay JY, Kerst JM, Sufliarsky J, Whelan J, Hohenberger P, et al: Doxorubicin alone versus intensified doxorubicin plus ifosfamide for first-line treatment of advanced or metastatic soft-tissue sarcoma: A randomised controlled phase 3 trial. Lancet Oncol 15: 415-423, 2014.

15. Yagita H, Takeda K, Hayakawa Y, Smyth MJ and Okumura K: TRAIL and its receptors as targets for cancer therapy. Cancer Sci 95: 777-783, 2004

16. Bouralexis S, Findlay DM and Evdokiou A: Death to the bad guys: Targeting cancer via Apo2L/TRAIL. Apoptosis 10: 35-51, 2005.

17. Rowinsky EK: Targeted induction of apoptosis in cancer management: The emerging role of tumor necrosis factor-related apoptosis-inducing ligand receptor activating agents. J Clin Oncol 23: 9394-9407, 2005.

18. Ashkenazi A, Pai RC, Fong S, Leung S, Lawrence DA, Marsters SA, Blackie C, Chang L, McMurtrey AE, Hebert A, et al: Safety and antitumor activity of recombinant soluble Apo2 ligand. J Clin Invest 104: 155-162, 1999.

19. Daniel P: Molecular principles of apoptosis. In: Principles of Molecular Medicine. Ganten D and Ruckpaul K (eds). 3rd edition. Springer, Berlin Heidelberg, pp159-203, 2008.

20. Newsom-Davis T, Prieske S and Walczak H: Is TRAIL the holy grail of cancer therapy? Apoptosis 14: 607-623, 2009.

21. LeBlanc HN and Ashkenazi A: Apo2L/TRAIL and its death and decoy receptors. Cell Death Differ 10: 66-75, 2003.

22. Chromik AM, Daigeler A, Bulut D, Flier A, May C, Harati K, Roschinsky J, Sülberg D, Ritter PR, Mittelkötter U, et al: Comparative analysis of cell death induction by Taurolidine in different malignant human cancer cell lines. J Exp Clin Cancer Res 29: 21, 2010.

23. Jacobi CA, Menenakos $\mathrm{C}$ and Braumann $\mathrm{C}$ : Taurolidine-a new drug with anti-tumor and anti-angiogenic effects. Anticancer Drugs 16: 917-921, 2005.

24. McCourt M, Wang JH, Sookhai S and Redmond HP: Taurolidine inhibits tumor cell growth in vitro and in vivo. Ann Surg Oncol 7: 685-691, 2000.

25. Petrovic L, Schlegel KA, Ries J, Park J, Diebel E, Schultze-Mosgau S and Wiltfang J: In vitro effect of taurolidine on squamous cell carcinoma in the oral cavity. Mund Kiefer Gesichtschir 7: 102-107, 2003 (In German).

26. Gallagher KA, Liu ZJ, Xiao M, Chen H, Goldstein LJ, Buerk DG, Nedeau A, Thom SR and Velazquez OC: Diabetic impairments in NO-mediated endothelial progenitor cell mobilization and homing are reversed by hyperoxia and SDF-1 alpha. J Clin Invest 117: 1249-1259, 2007.

27. Calabresi P, Goulette FA and Darnowski JW: Taurolidine: Cytotoxic and mechanistic evaluation of a novel antineoplastic agent. Cancer Res 61: 6816-6821, 2001.

28. Braumann C, Henke W, Jacobi CA and Dubiel W: The tumor-suppressive reagent taurolidine is an inhibitor of protein biosynthesis. Int J Cancer 112: 225-230, 2004.

29. Darnowski JW, Goulette FA, Cousens LP, Chatterjee D and Calabresi P: Mechanistic and antineoplastic evaluation of taurolidine in the DU145 model of human prostate cancer. Cancer Chemother Pharmacol 54: 249-258, 2004.

30. Stendel R, Biefer HR, Dékány GM, Kubota H, Münz C, Wang S, Mohler H, Yonekawa Y and Frei K: The antibacterial substance taurolidine exhibits anti-neoplastic action based on a mixed type of programmed cell death. Autophagy 5: 194-210, 2009. 
31. Stendel R, Scheurer L, Stoltenburg-Didinger G, Brock M and Möhler H: Enhancement of fas-ligand-mediated programmed cell death by taurolidine. Anticancer Res 23: 2309-2314, 2003.

32. Chromik AM, Daigeler A, Hilgert C, Bulut D, Geisler A, Liu V, Otte JM, Uhl W and Mittelkötter U: Synergistic effects in apoptosis induction by taurolidine and TRAIL in HCT-15 colon carcinoma cells. J Invest Surg 20: 339-348, 2007.

33. Daigeler A, Chromik AM, Geisler A, Bulut D, Hilgert C, Krieg A, Klein-Hitpass L, Lehnhardt M, Uhl W and Mittelkötter U: Synergistic apoptotic effects of taurolidine and TRAIL on squamous carcinoma cells of the esophagus. Int J Oncol 32: 1205-1220, 2008.

34. Daigeler A, Chromik AM, Haendschke K, Emmelmann S, Siepmann M, Hensel K, Schmitz G, Klein-Hitpass L, Steinau HU, Lehnhardt M and Hauser J: Synergistic effects of sonoporation and taurolidin/TRAIL on apoptosis in human fibrosarcoma. Ultrasound Med Biol 36: 1893-1906, 2010.

35. Karlisch C, Harati K, Chromik AM, Bulut D, Klein-Hitpass L, Goertz O, Hirsch T, Lehnhardt M, Uhl W and Daigeler A: Effects of TRAIL and taurolidine on apoptosis and proliferation in human rhabdomyosarcoma, leiomyosarcoma and epithelioid cell sarcoma. Int J Oncol 42: 945-956, 2013.

36. Daigeler A, Brenzel C, Bulut D, Geisler A, Hilgert C, Lehnhardt M, Steinau HU, Flier A, Steinstraesser L, Klein-Hitpass L, et al TRAIL and taurolidine induce apoptosis and decrease proliferation in human fibrosarcoma. J Exp Clin Cancer Res 27: 82, 2008.

37. Sun BS, Wang JH, Liu LL, Gong SL and Redmond HP: Taurolidine induces apoptosis of murine melanoma cells in vitro and in vivo by modulation of the Bcl-2 family proteins. J Surg Oncol 96: 241-248, 2007.

38. Nici L, Monfils B and Calabresi P: The effects of taurolidine, a novel antineoplastic agent, on human malignant mesothelioma. Clin Cancer Res 10: 7655-7661, 2004.
39. Arlt MJ, Walters DK, Banke IJ, Steinmann P, Puskas GJ, Bertz J, Rentsch KM, Ehrensperger F, Born W and Fuchs B: The antineoplastic antibiotic taurolidine promotes lung and liver metastasis in two syngeneic osteosarcoma mouse models and exhibits severe liver toxicity. Int J Cancer 131: E804-E812, 2012.

40. Marley K, Helfand SC, Simpson J, Mata JE, Tracewell WG, Brownlee L, Bracha S and Séguin B: Pharmacokinetic study and evaluation of the safety of taurolidine for dogs with osteosarcoma. J Exp Clin Cancer Res 32: 74, 2013.

41. Marley K, Helfand SC, Edris WA, Mata JE, Gitelman AI, Medlock $J$ and Séguin B: The effects of taurolidine alone and in combination with doxorubicin or carboplatin in canine osteosarcoma in vitro. BMC Vet Res 9: 15, 2013.

42. Braumann C, Winkler G, Rogalla P, Menenakos C and Jacobi CA Prevention of disease progression in a patient with a gastric cancer-re-recurrence. Outcome after intravenous treatment with the novel antineoplastic agent taurolidine. Report of a case. World J Surg Oncol 4: 34, 2006.

43. Möhler H, Pfirrmann RW and Frei K: Redox-directed cancer therapeutics: Taurolidine and piperlongumine as broadly effective antineoplastic agents (review). Int $\mathbf{J}$ Oncol 45: 1329-1336, 2014

44. Imhof L, Goldinger SM, Baumann K, Schad K, French LE, Röthlisberger $\mathrm{P}$ and Dummer R: The antibacterial substance, taurolidine in the second/third-line treatment of very advanced stage IV melanoma including brain metastases: Results of a phase 2, open-label study. Melanoma Res 21: 80-83, 2011.

45. Stendel R, Picht T, Schilling A, Heidenreich J, Loddenkemper C, Jänisch W and Brock M: Treatment of glioblastoma with intravenous taurolidine. First clinical experience. Anticancer Res 24: 1143-1147, 2004. 